\title{
The Research on Distribution of Lead-Time Demand on the Basis of Multivariate Higher-Order Markov Chain
}

\author{
Jiahui Xu' ${ }^{1}$ Pingyu Liu², Xuemin $\mathrm{Xu}^{3}$, Zhenni Huang ${ }^{4}$, Wenshuang Zhao ${ }^{5}$, Kwok Leung Tam ${ }^{6}$, \\ Aiping Jiang ${ }^{7 *}$
}

1,2,3,4,5,7SILC Business School, Shanghai University

20 Chengzhong Road, Jiading District, Shanghai 201899, China

E-mail.xjh517@shu.edu.cn; cat1357@yeah.net; xueminxu@shu.edu.cn; zhenni12@shu.edu.cn; zws365@163.com; ap724@shu.edu.cn (corresponding author)*

${ }^{6}$ School of Mathematics and Statistics, UNSW

Sydney NSW, 2052, Australia

E-mail.yves.tam@unsw.edu.au

cross $^{\text {ref }}$ http://dx.doi.org/10.5755/j01.ee.32.4.27571

Inventory management is an important part of supply chain management: inventory shortages could result in reduced delivery speeds and response speeds while excess inventory could lead to increased inventory and operating costs. Therefore, finding ways to efficiently control inventory has become an issue companies are most concerned about. Choosing a proper inventory management method based on the lead-time demand distribution fitted from historical data has become the key criteria to solve this issue. However, it is difficult to determine the lead-time distribution based on the limited amount of historical data directly. Thus, the method this report introduces uses a multivariate higher-order Markov chain to reconstruct historical data in order to expand the amount of data used to fit the lead-time distribution of demand, which is significant for inventory management.

Keywords: Forecasting; Lead-time Demand; Inventory Management; Supply Chain Management; Multivariate HigherOrder Markov Chain.

\section{Introduction}

If an enterprise wants to gain a firm and ongoing foothold in an increasingly competitive market, it must ceaselessly improve its speed of supply and its accounting efficiency while still ensuring the quality of its provided goods and services. Improving the efficiency and quality of supply are closely related to inventory management, and how well inventory management is performed has become one of the key issues of enterprise management.

Inventory management is the process of forecasting, planning, executing, and controlling stock replenishment order according to external requirements for inventory and characteristics of enterprise ordering, where two kinds of issues need to be considered. The first issue concerns the actual ordering stock in terms of time, approaches and amount. The second is to control the cost of ordering and inventories to maximize profits. Poor inventory management can lead to inefficiencies or excess stock. On the one hand, when enterprises face bulk orders, insufficient raw material inventory can result in failures in production and supply, and the lack of supplies for maintenance and infrastructure can reduce the speed at which businesses deal with emergencies, further slowing down supply rates due to the potential equipment downtime problems. On the other hand, overstocking can cause increased inventory costs, including storage costs and the natural wastage of goods, and result in reduced efficiency and liquidity of enterprise funds.
Therefore, the enactment of reasonable inventory management strategies, appropriate methods of calculating inventory levels, and reordering points, as well as other key issues in inventory management, can all improve the supply efficiency and quality of capital utilization and enhance the competitiveness of an enterprise.

The lead-time demand distribution according to historical data is often the presupposition and basis of selection and application of inventory management strategies. Therefore, the realization of lead-time demand distribution is one of the most important problems that must be solved in the inventory management process. However, the real lead-time demand data sample size used to fit distribution is often too small because of poor data management or limited period of demand. Therefore, this paper presents a multiple variable high-order Markov chain to reconstruct the historical demand data, expand the amount of data used to fit the distribution, and then obtain lead-time demand distribution. A lack of sufficient historical demand data in electric power enterprises is a major obstacle to obtaining the lead-time demand distribution, thus it is very difficult to control their inventory management. Considering the important role power enterprises play in business operation and residents' daily life, the empirical analysis part of this paper, which focuses on the solution of the leadtime demand distribution of power supplies in Shanghai Power Corporation, has important social significance. 
Jiahui Xu, Pingyu Liu, Xuemin Xu, Zhenni Huang, Wenshuang Zhao, Kwok Leung Tam, Aiping Jiang. The Research ...

\section{Literature Review}

Scholars have proposed their own inventory management strategies from different perspectives. Generally these can be classified into two categories:

The first type of research directly uses demand distribution to conduct inventory management. According to lead-time demand, which obeys both normal and Gamma distribution of spare parts, Strijbosch, Heuts and Van der Schoot (2000) put forward different inventory management models based on a (s, Q) strategy, providing optimal order quantity and order point, where s is the reorder point and Q is the order quantity. Elsayed and Teresi (1983) proposed another economic order quantity (EOQ) model for deteriorating products subject to normal distribution. Snyder (2002) used the Bernoulli distribution to determine the probability of demand occurrence, and then used the Bootstrap method to generate the lead demand for multiple sets of estimates in order to calculate service levels, reorder point and order quantity. In some studies, the demand sequence is fitted as a compound Bernoulli distribution, compound Poisson distribution, and compound Erlang distribution, and then put through cost-oriented modeling in order to gain the optimal inventory level under the minimum expected cost (Archibald \& Silver, 1978; Babai, Jemai, \& Dallery, 2011; Cheung, 1996; Feeney \& Sherbrooke, 1966; Larsen \& Thorstenson, 2008; Smith \& Dekker, 1997; Teunter, Syntetos, \& Babai, 2010). Unlike the inventory policies of continuous inspection adopted in the literature above, other studies adopted cyclical inspection strategies (Ehrhardt, 1979; Naddor, 1975; Porteus, 1985; Roberts, 1962; Veinott \& Wagner, 2011; Wagner, 1975). Sani and Kingsman (1997) performed a contrasting study of the various forms of $(\mathrm{T}, \mathrm{s}, \mathrm{S})$ algorithms mentioned in the above literature where $\mathrm{T}$ represents the time period that elapses between reviews and $\mathrm{S}$ is the replenishment level, and found that Power Approximation (Ehrhardt, 1979), Normal Approximation (Wagner, 1975) and Naddor's heuristic (Naddor, 1975) performed better with demand inventory control, and the difference between the three algorithms was small. Babai, Jema and Dallery (2011) conducted a similar study and found that Power Approximation and Naddor's heuristic were better in terms of calculating the optimal order-up-to level. Chelbi and Ait-Kadi (1999) discussed that when the life distribution, lead-time demand distribution, and replenishment parts inventory management costs are known, a numerical algorithm can optimize the storage strategy of spare parts.

The other kind of research combines the demand forecast value and the demand distribution to implement the stock management. Silver (1965) used the Bayesian method to forecast the demand, and then calculated the posterior probability to obtain the distribution of demand after the lead-time demand was calculated, thus the reorder point and order quantity were determined. Pilinkiene (2008) analysed how to select the appropriate market demand forecast methods to determine the Lithuanian furniture demand forecast. Teunter and Sani (2009) combined the demand forecast value and the lead-time demand distribution obtained by the Croston method to determine the maximum inventory level. Kourentzes (2013) used a neural network to forecast the demand, and then used the same strategy as
Teunter and Sani (2009) to manage the inventory. Chandra and Grabis (2005) applied an autoregressive model to the demand forecasting and proposed a material requirement planning based on inventory management method to reduce the order quantity variance. By applying an exponential smoothing method to make predictions, $\mathrm{Su}$ and Wong (2008) combined a $\left(\mathrm{k}, \mathrm{T}_{0}\right)$ and two-stage ant colony optimization to determine the optimal replenishment cycle $\left(\mathrm{T}_{0}\right)$ and the excess order quantity $(\mathrm{k})$ to compensate for demand fluctuations. Liu and Lian (1999) used the hidden Markov model to predict the demand for continuous review perishable inventory system, and put forward an $(\mathrm{s}, \mathrm{S})$ inventory model for fixed lifecycle goods with continuous demand. They found that the replenishment level (S) always increased monotonically with reorder level (s). Leven and Segerstedt (2004) calculated the lead-time probability for the shortage of two materials whose demand distribution satisfied the Erlang and normal distributions. They used a revised Croston method and an exponential smoothing method to forecast the demand and then established an inventory management model.

Although these two kinds of research have different perspectives on inventory management, they are proposed on the basis of known demand distribution of lead-time. As for those materials with historical data that are too small to fit, it is difficult to obtain a lead-time demand distribution, so these above inventory management methods cannot be directly applied. To solve this problem, Kocer (2013) proposed obtaining the lead-time demand distribution by using a single-variable high-order Markov chain model to reconstruct the historical demand data. Besides the limitation of small historical data samples, the uncertainty of known historical demand data also significantly influences the demand prediction. He and Jiang (2017) pointed out the limited application of the classical Discrete-time Markov chain (DTMC) in a complex system with uncertain information or continuous state space and proposed a new belief Markov chain to solve these problems based on Dempster-Shafer evidence theory. This model handles uncertain data in the form of interval numbers and generates a basic probability assignment based on the distance between interval numbers. However, in the application of the higher-order Markov chain these two methods only consider the autocorrelation of the demand time series of the material itself, but do not consider the lag of the interaction between different materials.

Additionally, in recent years the Markov chain model has been applied in solving variable problems from different aspects. Chiachío et al. (2020) stated that a prognostics methodology, which relies on a stochastic damage model based on Markov chains, could deal with complex degradation processes in metallic materials. Andersen, Nielsen and Reinhardt (2017) proposed a mathematical method to ensure adequate hospital beds by redistributing the existing wards in the hospital. The continuous-time Markov chain was used to model the patient flow, and the optimization was carried out using local search heuristics. Chen, Liu and Jiang (2021) solved the optimization problem of multi-state components system maintenance by using an embedded Markov chain model to characterize the deterioration of above system. Feldman and Topaloglu (2017) devised a Markov chain choice model to solve three 
classes of revenue management problems related to when customers choose from the offered products. Karapetyan, Punnen and Parkes (2017) designed a new metaheuristic schema called the Conditional Markov Chain Search which was flexible enough to model several standard metaheuristics when solving the Bipartite Boolean Quadratic Programming Problem.

This paper studies the inventory materials that are difficult to directly fit the lead-time demand distribution based on the limited amount of historical demand data. Applying the existing method that a single variable highorder Markov chain is used to solve the lead-time demand distribution, a multivariate high-order Markov chain is introduced by incorporating the interaction between materials. The multivariate high-order Markov chain reconstructs data to fit the lead-time demand distribution.

\section{Multivariate Higher-order Markov chain- Based Research on Distribution of Lead-Time Demand}

The traditional Markov chain is a fuzzy random model for demand forecasting. This model divides the real demand data into two statuses, either "happened" or "not happened", and then uses the autocorrelation of data sequences to maintain and pass the historical requirement information to the next point by a one-step transition probability matrix obtained by summarizing historical data. According to a single-variable high-order Markov chain model, Kocer (2013) proposed a method of obtaining lead-time demand distribution by reconstructing historical demand data. However, this method only considers the autocorrelation of a material's demand time series, not the interaction between different materials. Therefore, this paper takes the relative effects of different materials into account during the process of reconstructing the historical demand data by using a multivariate high-order Markov chain model, thus fixing the deficiencies of the method mentioned above.

In this paper, the Markov chain is considered as a tool for reconstructing historical data to obtain lead-time demand distribution. On the basis of the method proposed by Kocer, the dependence between different data sequences is introduced into the data processing, and then the lead-time demand distribution is obtained by using multivariate highorder Markov chain. Firstly, the demand data of each material is matched with the state. Secondly, the n-step transition probability matrix between one material and the other materials, as well as the transfer of the material itself, is calculated. The result is applied to a multivariate higherorder Markov chain model to derive a state probability vector at each time point within a new historical period. This is achieved by using the first few historical periods of demand data as the raw values of the later historical demand data. Then, taking the obtained probability as the weight, sampling of the demand quantity of each state is randomly repeated to form the new historical demand sequence. Finally, the lead-time demand distribution is fitted by combining the new requirement sequences and lead-times.

In order to state the multivariate higher-order Markov chain more explicitly, some explanation is required before each specific state. In a single variable higher order Markov chain, since there is more than one transition probability, the state probability vector formula is:

$$
\tilde{X}^{t}=\sum_{i=1}^{n} \lambda_{i} P^{i} X^{(\mathrm{t}-i)}
$$

According to formula (2), the corresponding weight $\lambda_{i}$ of each transfer matrix $P^{i}$ is also required. The optimization model of the solution is shown in (2):

$$
\sum_{i}^{n} Q^{i} \hat{\mathrm{X}} \approx \hat{\mathrm{X}}
$$

That is, satisfying:

$$
\min _{\lambda} \max \left|\left[\sum_{i}^{n} Q^{i} \hat{\mathrm{X}} \approx \hat{\mathrm{X}}\right]_{k}\right|
$$

Formula (3) is obtained by the deformation of (2):

$$
\left\{\begin{array}{l}
\left.\underset{\omega}{\min \lambda} \begin{array}{l}
\omega \\
\omega \\
\ldots \\
\omega
\end{array}\right) \geq \hat{X}-\left[Q^{1}\left|Q^{2} \ldots\right| Q^{n}\right]\left(\begin{array}{l}
\bar{\lambda}_{1} \\
\bar{\lambda}_{2} \\
\ldots \\
\bar{\lambda}_{n}
\end{array}\right) \\
\left(\begin{array}{l}
\omega \\
\omega \\
\ldots \\
\omega
\end{array}\right) \geq-\hat{X}+\left[Q^{1}\left|Q^{2} \ldots\right| Q^{n}\right]\left(\begin{array}{l}
\bar{\lambda}_{1} \\
\bar{\lambda}_{2} \\
\ldots \\
\bar{\lambda}_{n}
\end{array}\right) \\
\omega \geq 0 \quad \lambda_{i} \geq 0 \\
\sum_{i}^{n} \lambda_{i}=1
\end{array}\right.
$$

where $Q^{1}=\hat{X} \times P^{1} \quad, \quad Q^{2}=\hat{X} \times P^{2} \quad \ldots \quad Q^{n}=\hat{X} \times P^{n}$. $\hat{X}$ represents the steady-state state vector, which is characterized by the probability distribution of each state of the known historical interval. For a careful deformation process, the reader is referred to a technical article: Ching, Fung and $\mathrm{Ng}$ (2004).

Based on the interaction of different demand sequences in multivariate high-order Markov chain, the order of each two sequences is first determined by their cross-correlation function. Then the maximum order is selected as the order of the model. Let multivariate demand sequence samples be $\left\{x_{t}^{k}, k=1,2, \cdots, \mathrm{s} ; \mathrm{t}=1,2, \cdots N\right\}$.The cross-correlation function between sequences $i$ and $j$ is:

$$
\begin{aligned}
r^{i j}(d) & =\frac{c^{i j}(d)}{\sqrt{c^{i i}(0) c^{i j}(0)}} \\
& =\frac{\sum_{t=1}^{N-d}\left(\mathrm{x}_{t}^{i}-\overline{\mathrm{x}}^{i}\right)\left(\mathrm{x}_{t+d}^{j}-\overline{\mathrm{x}}^{j}\right)}{\sqrt{\sum_{t=1}^{N}\left(\mathrm{x}_{t}^{i}-\overline{\mathrm{x}}^{i}\right)^{2} \sum_{t=1}^{N}\left(\mathrm{x}_{t}^{j}-\overline{\mathrm{x}}^{j}\right)^{2}}}
\end{aligned}
$$

where $c^{i j}(d)=\frac{1}{N} \sum_{t=1}^{N-d}\left(\mathrm{x}_{t+d}^{i}-\overline{\mathbf{x}}^{i}\right)\left(\mathrm{x}_{t}^{j}-\overline{\mathbf{x}}^{j}\right), d=0,1, \cdots, N-1$, $1 \leq i \leq s, 1 \leq j \leq s$

The order between demand sequences $i$ and $j$ can be determined as the value $d^{i j}$ the moment the crosscorrelation function $r^{i j}(d)$ between two sequences reaches 
Jiahui Xu, Pingyu Liu, Xuemin Xu, Zhenni Huang, Wenshuang Zhao, Kwok Leung Tam, Aiping Jiang. The Research ...

zero. A correlation between sequences $i$ and $j$ exists when $d \leq d^{i j}$, otherwise it is considered that there is no correlation. The order $n$ of the multivariate high-order Markov model should be taken as:

$$
n=\max _{1 \leq i \leq s, 1 \leq j \leq s}\left\{d^{i j}\right\}
$$

In the multivariate higher-order Markov chain, the solving method of multivariate multi-step transfer probability matrix $P_{h}^{j k}$ is basically the same as that of single variable multi-step transition probability matrix, but the calculation of multi-step transfer frequency transferred from all other sequences to this sequence needs to be considered. Ching (2002) provided an example to explain the multi-step transition probability matrix between different sequences. Since the transition probability matrix occurs with the multi-step transition matrix of the sequence itself, there are other transition probability sequences for the matrix. Therefore, the optimal solving model of weight $\lambda_{j k}^{h}$ corresponding to the transition probability matrix $P_{h}^{j k}$ is more complicated than the one cited by single variable high order models, which is shown in formula (6).

$$
\left\{\begin{array}{l}
\min _{\lambda_{i j}}\|\hat{X}-\hat{X} Q\| \\
\sum_{k=1}^{s} \sum_{h=1}^{n} \lambda_{i j}^{h}=1 \\
\lambda_{i j}^{h} \geq 0
\end{array}\right.
$$

where $\quad \hat{X}=\left(\left(\hat{x}^{1}\right)^{T},\left(\hat{x}^{2}\right)^{T}, \ldots,\left(\hat{x}^{S}\right)^{T}\right) \quad, \quad Q=\left(Q_{1}, Q_{2} \ldots \mathrm{Q}_{s}\right) ，$ $Q_{j}=\left[P_{1}^{j 1} \hat{X}^{1}\left|\ldots P_{n}^{j 1} \hat{X}^{1}\right| P_{1}^{j 2} \hat{X}^{2} \ldots\left|P_{n}^{j 2} \hat{X}^{2} \ldots\right| P_{1}^{j s} \hat{X}^{s} \mid \ldots P_{n}^{j s} \hat{X}^{s}\right]$.

Formula (7) is obtained by deformation:

$$
\left\{\begin{array}{l}
\min _{\lambda} \omega_{j} \\
\left(\begin{array}{l}
\omega_{j} \\
\omega_{j} \\
\ldots \\
\omega_{j}
\end{array}\right) \geq \hat{X}^{j}-Q_{j}\left(\begin{array}{l}
\bar{\lambda}_{j 1} \\
\bar{\lambda}_{j 2} \\
\cdots \\
\bar{\lambda}_{j 3}
\end{array}\right) \\
\left(\begin{array}{l}
\omega_{j} \\
\omega_{j} \\
\cdots \\
\omega_{j}
\end{array}\right) \geq-\hat{X}^{j}+Q_{j}\left(\begin{array}{l}
\bar{\lambda}_{j 1} \\
\bar{\lambda}_{j 2} \\
\cdots \\
\bar{\lambda}_{j 3}
\end{array}\right) \\
\omega_{j} \geq 0 \\
\sum_{k=1}^{s} \sum_{h=1}^{n} \lambda_{i j}^{h}=1
\end{array}\right.
$$

where $\bar{\lambda}_{j h}=\left(\bar{\lambda}_{j h}^{1}, \bar{\lambda}_{j h}^{2} \ldots . . \bar{\lambda}_{j h}^{n}\right)^{T}$.

The specific process of reconstructing historical data is as follows:

Step 1. Selecting $s$ materials, the demand quantity of each one is standardized and the states are set according to the same standard. Among them, the state for the highfrequency demand is individually set, and the state for the low-frequency demand is set according to the equal interval length after standardization.

Step 2. The cross-correlation order between each of the two materials is determined according to the dependence of different materials. The maximum is chosen as the order of the Markov chain.

Step 3. Finding the h-step transition matrix $P_{h}^{j k}(h=1,2, \cdots, n ; j, k=1,2, \cdots, \mathrm{s}) . P_{h}^{j k}$ is the h-step transition matrix from the $k$ th material to the $j$ th material.

Step 4. According to the stationary state vector and the multistep transition matrix, an optimization model is established to determine the coefficients $\lambda_{j k}^{h}$ of the h-step transition matrix $P_{h}^{j k}$ (where $\lambda_{j k}^{h} \geq 0$

$$
\text { and } \left.\sum_{k=1}^{s} \sum_{h}^{n} \lambda_{j k}^{h}=1, j=1,2, \cdots, \mathrm{s}\right) \text {. }
$$

Step 5. The multiple higher-order Markov formula is used to obtain the state probability vector $\tilde{X}_{t+1}^{j}$ at time $t+1$ of the $k$ th material:

$$
\tilde{X}_{t+1}^{j}=\sum_{k=1}^{s} \sum_{h=1}^{n} \lambda_{j k}^{h} P_{h}^{j k} X_{t-h+1}^{k}
$$

where $X_{t-h+1}^{k}$ is the actual state probability vector of the $k$ th material at time $(t-h+1)$.

Step 6. The probability value of each state in $\tilde{X}_{t+1}^{j}$ is used as the weight of the corresponding demand quantity of the $j$ th material in different states, where the probability of a state composed of a plurality of demand quantities will be evenly assigned to each demand of the group. Next, random sampling is conducted according to the weight and then the new demand sequence is reconstructed based on historical data, followed by repeated sampling to obtain several multiple demand sequences.

Step 7. The accuracy $r^{j}$ of each reconstructed demand sequence for the $j$ th material is calculated, and then the largest one is selected as the finalized accuracy of reconstructed demand sequences. The definition of $r^{j}$ is as follows:

$$
\begin{aligned}
& r^{j}=\frac{1}{T^{j}-n} \sum_{t=n+1}^{T^{j}} U_{t}^{j} \\
& \text { where } U_{t}^{j}=\left\{\begin{array}{ll}
1 & \overline{\mathrm{D}}_{t}^{j}=\mathrm{D}_{t}^{j} \\
0 & \text { otherwise }
\end{array}, T^{j} \text { is the length of the } j\right. \text { th }
\end{aligned}
$$

material requirement sequence. $\overline{\mathrm{D}}_{t}^{j}$ is the value of the demand of the $j$ th material at time $t$ obtained from random sampling according to the probability. $\mathrm{D}_{t}^{j}$ is the actual demand of the $j$ th material at the time $t$ in the historical data.

Step 8. Steps six and seven are repeated several times to obtain sets of reconstructed demand data in the historical period.

Step 9. According to the fixed lead-time, the sets of reconstructed demand data are summed as lead-time demand data, and the lead-time demand distribution is obtained by fitting these data.

\section{Empirical Analysis}

Selecting 50 kinds of power supplies from the Shanghai Power Corporation, this study empirically researches monthly demand data for 36 months from 2011 to 2013. In order to show the operation process of multivariate highorder Markov chain, this paper further selects five kinds of materials belonging to the same subclass, whose cross- 
correlation coefficients are relatively large, to obtain the lead-time demand distribution of each group. It should be pointed out that in practical application, material selection can be arbitrary, and there is no need to use categories as criteria for selection. The basic information of the five materials in this example is shown in Table 1.

Firstly, the demand quantity of each material is standardized and then conditions set according to the same standard. Among them, the state is individually set for the high-frequency demand, and the state group for the low- frequency demand is set according to the equal interval length after standardization.

Because the standardized data of these five materials in this example have a stronger jump when the value is larger than 1, after standardization, the demands which are greater than 1 are divided into one group to have one state. The other standardized data are divided into three groups on average to set three different states. However, due to the different data characteristics of different materials, the state setting standards should be considered individually.

Table 1

Basic Information of Materials

\begin{tabular}{|c|c|c|c|c|}
\hline Material & Models & $\begin{array}{c}\text { Sub-subclass } \\
\text { description }\end{array}$ & $\begin{array}{c}\text { Subclass } \\
\text { description }\end{array}$ & $\begin{array}{c}\text { Class } \\
\text { description }\end{array}$ \\
\hline 500031139 & $\begin{array}{l}10 \mathrm{kV} \text { cable terminations, } 3 * 400 \text {, indoor terminals, } \\
\text { prefabricated, Cuprum }\end{array}$ & $\begin{array}{l}35 \mathrm{kV} \text { and below cable } \\
\text { terminals }\end{array}$ & Cable accessories & Device material \\
\hline 500021270 & $\begin{array}{l}10 \mathrm{kV} \text { cable terminations, } 3 * 120 \text {, indoor terminals, } \\
\text { prefabricated, Cuprum }\end{array}$ & $\begin{array}{l}35 \mathrm{kV} \text { and below cable } \\
\text { terminals }\end{array}$ & Cable accessories & Device material \\
\hline 500032513 & $\begin{array}{l}10 \mathrm{kV} \text { cable terminations, } 3 * 240 \text {, indoor terminals, } \\
\text { prefabricated, Cuprum }\end{array}$ & $\begin{array}{l}35 \mathrm{kV} \text { and below cable } \\
\text { terminals }\end{array}$ & Cable accessories & Device material \\
\hline 500021283 & $\begin{array}{l}10 \mathrm{kV} \text { cable terminations, } 3 * 120 \text {, outdoor } \\
\text { terminals, prefabricated, Cuprum }\end{array}$ & $\begin{array}{l}35 \mathrm{kV} \text { and below cable } \\
\text { terminals }\end{array}$ & Cable accessories & Device material \\
\hline 500032519 & $\begin{array}{l}10 \mathrm{kV} \text { cable terminations, } 3 * 70 \text {, indoor terminals, } \\
\text { prefabricated, Cuprum }\end{array}$ & $\begin{array}{l}35 \mathrm{kV} \text { and below cable } \\
\text { terminals }\end{array}$ & Cable accessories & Device material \\
\hline
\end{tabular}

Table 2

Material State Distribution

\begin{tabular}{|c|c|c|c|c|c|c|}
\hline & & \multicolumn{5}{|c|}{ State } \\
\hline & & $\mathbf{1}$ & 2 & 3 & 4 & 5 \\
\hline \multirow{2}{*}{$\begin{array}{l}500031139 \\
\text { Material } 1\end{array}$} & Demand & 0 & $\begin{array}{c}3,7,14,15,16,19,21, \\
22\end{array}$ & $27,31,32,34,41$ & $42,45,46,50,54,55$ & $72,75,87,90$ \\
\hline & $\begin{array}{l}\text { Standardized } \\
\text { range }\end{array}$ & -1.27 & $(-1.15,-0.39)$ & $(-0.19,0.38)$ & $(0.42,0.94)$ & $(1.63,2.35)$ \\
\hline \multirow{2}{*}{$\begin{array}{l}500021270 \\
\text { Material } 2\end{array}$} & Demand & 0 & $2,3,8,28$ & $\begin{array}{c}35,37,38,43,52,54,60 \\
63,64\end{array}$ & $\begin{array}{c}67,69,70,72,73,74,77 \\
88,89,92,95,96\end{array}$ & $102,103,106,114,138$ \\
\hline & $\begin{array}{l}\text { Standardized } \\
\text { range }\end{array}$ & -1.61 & $(-1.56,-0.85)$ & $(-0.66,0.13)$ & $(0.21,1.00)$ & $(1.16,2.14)$ \\
\hline \multirow{2}{*}{$\begin{array}{l}500032513 \\
\text { Material } 3\end{array}$} & Demand & 0 & $\begin{array}{c}1,2,4,5,7,12,13,14 \\
15,17\end{array}$ & $\begin{array}{c}20,21,22,23,26,29,34, \\
35,39\end{array}$ & $43,45,46,50,51,60$ & $98,103,110,126$ \\
\hline & $\begin{array}{l}\text { Standardized } \\
\text { range }\end{array}$ & -0.99 & $(-0.96,-0.47)$ & $(-0.37,0.21)$ & $(0.33,0.86)$ & $(2.03,2.89)$ \\
\hline \multirow{2}{*}{$\begin{array}{l}500021283 \\
\text { Material } 4\end{array}$} & Demand & 0 & $1,3,4,8,9$ & $10,12,13,14,15,16,18$ & $20,21,22$ & $25,29,30,31,32$ \\
\hline & $\begin{array}{c}\text { Standardized } \\
\text { range }\end{array}$ & -1.48 & $(-1.37,-0.50)$ & $(-0.39,0.48)$ & $(0.70,0.91)$ & $(1.24,2.00)$ \\
\hline \multirow{2}{*}{$\begin{array}{l}500032519 \\
\text { Material } 5\end{array}$} & Demand & 0 & $1,4,10,14,24$ & $\begin{array}{c}40,43,44,48,50,55,56 \\
57,61,64\end{array}$ & $\begin{array}{c}69,78,79,85,95,100, \\
101\end{array}$ & $\begin{array}{c}107,109,113,115,127, \\
149\end{array}$ \\
\hline & $\begin{array}{l}\text { Standardized } \\
\text { range }\end{array}$ & -1.4 & $(-1.38,-0.84)$ & $(-0.46,0.10)$ & $(0.22,0.97)$ & $(1.11,2.10)$ \\
\hline
\end{tabular}

Taking material 500032513 as an example, a higher frequency demand 0 is set as state 1 , and the demand whose standardized value is greater than 1 , such as 98, 103, 110 and 126, is divided into one group set as state 5 . Since the difference between the maximum and minimum values of the remaining standardized data is about 1.5 , they are divided into three groups with 0.5 intervals, thus three states are set. That is, the standard data of demand in the range between -0.96 to 0.47 are grouped as state 2 , the standard data of demand in the range between -0.37 to 0.21 are grouped as state 3 , and the standard data of demand in the range of 0.33 to 0.86 are grouped as state 4 . The same method is used to set the states for five materials. The concrete conditions of the five sets of materials are set out in Table 2.

Then, according to the cross correlation between each two of the five materials' demand sequences, the order of cross correlation between the materials is obtained, and the maximum one is 3, which is the higher-order Markov chain. Therefore, the five-variate third-order Markov chain model is used for subsequent calculation.

Then, the transition frequency matrix $F_{h}^{1 k}$ is calculated along with the corresponding transition probability matrix $P_{h}^{1 k}$ of the four materials to material 1 , as well as the transition frequency matrix $F_{h}^{11}$ of material 1 itself and its corresponding transition probability matrix $P_{h}^{11}$. Since the case of five materials interacting each other is a third-order Markov process, a total of 15 transition probability matrix for the material 1 can be obtained. The transition frequency matrix and the transition probability matrix for material 1 are shown as follows: 
Jiahui Xu, Pingyu Liu, Xuemin Xu, Zhenni Huang, Wenshuang Zhao, Kwok Leung Tam, Aiping Jiang. The Research ...

$$
\begin{aligned}
& F_{1}^{11}=\left(\begin{array}{lllll}
2 & 3 & 0 & 0 & 0 \\
0 & 2 & 3 & 3 & 2 \\
0 & 1 & 2 & 4 & 1 \\
0 & 0 & 5 & 2 & 1 \\
0 & 0 & 0 & 3 & 1
\end{array}\right) P_{1}^{11}=\left(\begin{array}{ccccc}
1.00 & 0.50 & 0.00 & 0.00 & 0.00 \\
0.00 & 0.33 & 0.30 & 0.25 & 0.40 \\
0.00 & 0.17 & 0.20 & 0.33 & 0.20 \\
0.00 & 0.00 & 0.50 & 0.17 & 0.20 \\
0.00 & 0.00 & 0.00 & 0.25 & 0.20
\end{array}\right) \\
& F_{2}^{11}=\left(\begin{array}{lllll}
1 & 3 & 0 & 0 & 0 \\
1 & 1 & 3 & 3 & 2 \\
0 & 1 & 4 & 2 & 1 \\
0 & 1 & 3 & 3 & 1 \\
0 & 0 & 0 & 3 & 1
\end{array}\right) P_{2}^{11}=\left(\begin{array}{ccccc}
0.50 & 0.50 & 0.00 & 0.00 & 0.00 \\
0.50 & 0.17 & 0.30 & 0.27 & 0.40 \\
0.00 & 0.17 & 0.40 & 0.18 & 0.20 \\
0.00 & 0.17 & 0.30 & 0.27 & 0.20 \\
0.00 & 0.00 & 0.00 & 0.27 & 0.20
\end{array}\right) \\
& F_{3}^{11}=\left(\begin{array}{lllll}
2 & 2 & 0 & 0 & 0 \\
0 & 1 & 4 & 2 & 2 \\
0 & 1 & 2 & 3 & 2 \\
0 & 2 & 3 & 3 & 0 \\
0 & 0 & 1 & 2 & 1
\end{array}\right) P_{3}^{11}=\left(\begin{array}{ccccc}
1.00 & 0.33 & 0.00 & 0.00 & 0.00 \\
0.00 & 0.17 & 0.40 & 0.20 & 0.40 \\
0.00 & 0.17 & 0.20 & 0.30 & 0.40 \\
0.00 & 0.33 & 0.30 & 0.30 & 0.00 \\
0.00 & 0.00 & 0.10 & 0.20 & 0.20
\end{array}\right) \\
& F_{3}^{12}=\left(\begin{array}{lllll}
2 & 2 & 0 & 0 & 0 \\
1 & 2 & 3 & 3 & 0 \\
0 & 4 & 1 & 3 & 0 \\
0 & 4 & 4 & 0 & 0 \\
0 & 0 & 2 & 1 & 1
\end{array}\right) P_{3}^{12}=\left(\begin{array}{ccccc}
0.67 & 0.17 & 0.00 & 0.00 & 0.00 \\
0.33 & 0.17 & 0.30 & 0.43 & 0.00 \\
0.00 & 0.33 & 0.10 & 0.43 & 0.00 \\
0.00 & 0.33 & 0.40 & 0.00 & 0.00 \\
0.00 & 0.00 & 0.20 & 0.14 & 1.00
\end{array}\right) \\
& F_{1}^{13}=\left(\begin{array}{ccccc}
2 & 3 & 0 & 0 & 0 \\
1 & 4 & 3 & 1 & 1 \\
0 & 2 & 3 & 2 & 1 \\
0 & 1 & 4 & 2 & 1 \\
0 & 1 & 1 & 1 & 1
\end{array}\right) P_{1}^{13}=\left(\begin{array}{ccccc}
0.67 & 0.27 & 0.00 & 0.00 & 0.00 \\
0.33 & 0.36 & 0.27 & 0.17 & 0.25 \\
0.00 & 0.18 & 0.27 & 0.33 & 0.25 \\
0.00 & 0.09 & 0.36 & 0.33 & 0.25 \\
0.00 & 0.09 & 0.09 & 0.17 & 0.25
\end{array}\right) \\
& F_{2}^{13}=\left(\begin{array}{ccccc}
0 & 4 & 0 & 0 & 0 \\
2 & 1 & 4 & 1 & 2 \\
1 & 2 & 3 & 2 & 0 \\
0 & 3 & 2 & 2 & 1 \\
0 & 1 & 2 & 1 & 0
\end{array}\right) P_{2}^{13}=\left(\begin{array}{ccccc}
0.00 & 0.36 & 0.00 & 0.00 & 0.00 \\
0.67 & 0.09 & 0.36 & 0.17 & 0.67 \\
0.33 & 0.18 & 0.27 & 0.33 & 0.00 \\
0.00 & 0.27 & 0.18 & 0.33 & 0.33 \\
0.00 & 0.09 & 0.18 & 0.17 & 0.00
\end{array}\right) \\
& F_{3}^{13}=\left(\begin{array}{ccccc}
1 & 3 & 0 & 0 & 0 \\
0 & 2 & 4 & 2 & 1 \\
1 & 3 & 1 & 2 & 1 \\
1 & 2 & 4 & 0 & 1 \\
0 & 1 & 1 & 2 & 0
\end{array}\right) P_{3}^{13}=\left(\begin{array}{ccccc}
0.33 & 0.27 & 0.00 & 0.00 & 0.00 \\
0.00 & 0.18 & 0.40 & 0.33 & 0.33 \\
0.33 & 0.27 & 0.10 & 0.33 & 0.33 \\
0.33 & 0.18 & 0.40 & 0.00 & 0.33 \\
0.00 & 0.09 & 0.10 & 0.33 & 0.00
\end{array}\right) \\
& F_{1}^{14}=\left(\begin{array}{lllll}
4 & 1 & 0 & 0 & 0 \\
0 & 4 & 3 & 2 & 1 \\
0 & 1 & 4 & 2 & 1 \\
0 & 0 & 4 & 2 & 2 \\
0 & 0 & 0 & 2 & 2
\end{array}\right) P_{1}^{14}=\left(\begin{array}{ccccc}
1.00 & 0.17 & 0.00 & 0.00 & 0.00 \\
0.00 & 0.67 & 0.27 & 0.25 & 0.17 \\
0.00 & 0.17 & 0.36 & 0.25 & 0.17 \\
0.00 & 0.00 & 0.36 & 0.25 & 0.33 \\
0.00 & 0.00 & 0.00 & 0.25 & 0.33
\end{array}\right) \\
& F_{2}^{14}=\left(\begin{array}{lllll}
2 & 2 & 0 & 0 & 0 \\
2 & 0 & 5 & 1 & 2 \\
0 & 2 & 3 & 2 & 1 \\
0 & 2 & 3 & 2 & 1 \\
0 & 0 & 0 & 3 & 1
\end{array}\right) P_{2}^{14}=\left(\begin{array}{lllll}
0.50 & 0.33 & 0.00 & 0.00 & 0.00 \\
0.50 & 0.00 & 0.45 & 0.13 & 0.40 \\
0.00 & 0.33 & 0.27 & 0.25 & 0.20 \\
0.00 & 0.33 & 0.27 & 0.25 & 0.20 \\
0.00 & 0.00 & 0.00 & 0.38 & 0.20
\end{array}\right)
\end{aligned}
$$$$
\begin{aligned}
F_{3}^{14} & =\left(\begin{array}{lllll}
2 & 2 & 0 & 0 & 0 \\
1 & 1 & 3 & 3 & 1 \\
1 & 1 & 2 & 2 & 2 \\
0 & 2 & 6 & 0 & 0 \\
0 & 0 & 0 & 2 & 2
\end{array}\right) P_{3}^{14}=\left(\begin{array}{lllll}
0.50 & 0.33 & 0.00 & 0.00 & 0.00 \\
0.25 & 0.17 & 0.27 & 0.43 & 0.20 \\
0.25 & 0.17 & 0.18 & 0.29 & 0.40 \\
0.00 & 0.33 & 0.55 & 0.00 & 0.00 \\
0.00 & 0.00 & 0.00 & 0.29 & 0.40
\end{array}\right) \\
F_{1}^{15} & =\left(\begin{array}{lllll}
4 & 1 & 0 & 0 & 0 \\
2 & 3 & 4 & 1 & 0 \\
0 & 3 & 0 & 5 & 0 \\
0 & 3 & 3 & 2 & 0 \\
0 & 0 & 1 & 0 & 3
\end{array}\right) P_{1}^{15}=\left(\begin{array}{lllll}
0.67 & 0.10 & 0.00 & 0.00 & 0.00 \\
0.33 & 0.30 & 0.50 & 0.13 & 0.00 \\
0.00 & 0.30 & 0.00 & 0.63 & 0.00 \\
0.00 & 0.30 & 0.38 & 0.25 & 0.00 \\
0.00 & 0.00 & 0.13 & 0.00 & 1.00
\end{array}\right) \\
F_{2}^{15} & =\left(\begin{array}{lllll}
3 & 1 & 0 & 0 & 0 \\
2 & 1 & 3 & 4 & 0 \\
1 & 4 & 2 & 1 & 0 \\
0 & 4 & 2 & 2 & 0 \\
0 & 0 & 1 & 1 & 2
\end{array}\right) P_{2}^{15}=\left(\begin{array}{lllll}
0.50 & 0.10 & 0.00 & 0.00 & 0.00 \\
0.33 & 0.10 & 0.38 & 0.50 & 0.00 \\
0.17 & 0.40 & 0.25 & 0.13 & 0.00 \\
0.00 & 0.40 & 0.25 & 0.25 & 0.00 \\
0.00 & 0.00 & 0.13 & 0.13 & 1.00
\end{array}\right) \\
F_{3}^{15} & =\left(\begin{array}{lllll}
3 & 1 & 0 & 0 & 0 \\
1 & 3 & 2 & 3 & 0 \\
1 & 3 & 2 & 2 & 0 \\
1 & 2 & 3 & 2 & 0 \\
0 & 1 & 1 & 1 & 1
\end{array}\right) P_{3}^{15}=\left(\begin{array}{lllll}
0.50 & 0.10 & 0.00 & 0.00 & 0.00 \\
0.17 & 0.30 & 0.25 & 0.38 & 0.00 \\
0.17 & 0.30 & 0.25 & 0.25 & 0.00 \\
0.17 & 0.20 & 0.38 & 0.25 & 0.00 \\
0.00 & 0.10 & 0.13 & 0.13 & 1.00
\end{array}\right)
\end{aligned}
$$

The transition frequency matrix is individually related to the transition probability matrix for four other materials, and can be obtained by the same method.

Then, the probability vectors of the five stable states of the materials are obtained by the frequency of corresponding states of the actual historical demand of each material, which is shown in Table 3.

$$
\left\{\begin{array}{l}
\hat{x}^{1}=(0.16667,0.27778,0.22222,0.22222,0.11111) \\
\hat{x}^{2}=(0.05556,0.16667,0.27778,0.36111,0.13889) \\
\hat{x}^{3}=(0.08333,0.33333,0.27778,0.19444,0.11111) \\
\hat{x}^{4}=(0.08333,0.30556,0.30556,0.16667,0.13889) \\
\hat{x}^{5}=(0.11111,0.16667,0.30556,0.22222,0.19444)
\end{array}\right.
$$

Table 3

Frequency of Each State of the Historical Sequence

\begin{tabular}{|c|c|c|c|c|c|c|}
\hline \multirow{2}{*}{ Material 1 } & State & 1 & 2 & 3 & 4 & 5 \\
\cline { 2 - 7 } & Frequency & 6 & 10 & 8 & 8 & 4 \\
\hline \multirow{2}{*}{ Material 2 } & State & 1 & 2 & 3 & 4 & 5 \\
\cline { 2 - 7 } & Frequency & 2 & 6 & 10 & 13 & 5 \\
\hline \multirow{2}{*}{ Material 3 } & State & 1 & 2 & 3 & 4 & 5 \\
\cline { 2 - 7 } & Frequency & 3 & 12 & 10 & 7 & 4 \\
\hline \multirow{2}{*}{ Material 4 } & State & 1 & 2 & 3 & 4 & 5 \\
\cline { 2 - 7 } & Frequency & 3 & 11 & 11 & 6 & 5 \\
\hline \multirow{2}{*}{ Material 5 } & State & 1 & 2 & 3 & 4 & 5 \\
\cline { 2 - 7 } & Frequency & 4 & 6 & 11 & 8 & 7 \\
\hline
\end{tabular}

Then, according to formula (7) shown above and still using material 1 as an example, we can obtain the corresponding weight $\lambda_{1 k}^{h}$ of the transition probability matrix $P_{h}^{1 k}$ of material 1 through the following two sets of inequalities:

The result is that $\lambda_{11}^{2}=0.2, \lambda_{11}^{3}=0.2, \lambda_{13}^{2}=0.2$, $\lambda_{13}^{3}=0.2, \lambda_{15}^{2}=0.2$ and the others are 0 . From this we can see that material 1 subjects to the third-order effect from the five existing materials, where the first-order effect does not 
exist, indicating that all material effects on material 1 are not immediately reflected; the second-order influence mainly comes from material 1 itself, and materials 3 and 5, which shows that the influences on material 1 coming from materials 1, 3 and 5 have a two-step lag; the third-order influence mainly comes from material 1 itself and material 3 , indicating that the influences to material 1 come from materials 1 and 3 with a three-step lag.

Thus, the third-order Markov chain model of material 1 can be obtained according to the weight calculated by formula (6), as shown in formula (10):

$$
\begin{aligned}
\tilde{X}_{t+1}^{1}= & 0.2 P_{2}^{11} X_{t-1}^{1}+0.2 P_{3}^{11} X_{t-2}^{1}+0.2 P_{2}^{13} X_{t-1}^{3} \\
& +0.2 P_{3}^{13} X_{t-2}^{3}+0.2 P_{3}^{15} X_{t-2}^{5}
\end{aligned}
$$

In the same way, we construct the Markov chains for the four other materials, and obtain their third-order Markov chain model, as follows:

$$
\begin{aligned}
& \tilde{X}_{t+1}^{2}=0.2 P_{1}^{21} X_{t}^{1}+0.6 P_{2}^{21} X_{t-1}^{1}+0.2 P_{1}^{42} X_{t}^{2} \\
& \tilde{X}_{t+1}^{3}=0.2 P_{1}^{31} X_{t}^{1}+0.2 P_{1}^{33} X_{t}^{3}+0.6 P_{3}^{34} X_{t-2}^{4} \\
& \tilde{X}_{t+1}^{4}=0.4 P_{1}^{41} X_{t}^{1}+0.2 P_{3}^{43} X_{t-2}^{3}+0.4 P_{3}^{44} X_{t-2}^{4} \\
& \tilde{X}_{t+1}^{5}=0.6 P_{2}^{51} X_{t-1}^{1}+0.2 P_{3}^{51} X_{t-2}^{1}+0.2 P_{1}^{54} X_{t}^{4}
\end{aligned}
$$

Then, the historical requirements of the first three months of each material are put into the formulas (10-14) to successively obtain the probability vectors of each material from month 4 to month 36 .

Next, in order to easily facilitate the process of steps 6 to 9 , we illustrate them with material 1 as an example.

The probability of each state is assigned to the corresponding demand quantity, where the demand quantity of the same state averages the probability of the occurrence of the state. When $t+1=5$, the probability vectors for the states are $(0.4594,0.0715,0.2164,0.2345,0.0182)$. Because only state 1 corresponds to demand 0 , the probability of 0 is 0.4594 ; because the probability of the occurrence of state 2 is 0.0715 , and because it contains 10 corresponding demands, the average probability of the occurrence of these 10 demands corresponding to that state is $0.0715 / 10=0.00715$. Similarly, the average probability of the occurrence of eight other demands corresponding to state 3 is $0.2164 / 8=0.02705$; the average probability of the occurrence of eight other demands corresponding to state 4 is $0.2345 / 8=0.02932$; the average probability of the occurrence of four other demands corresponding to state 5 is $0.0182 / 4=0.0045$. In the same way, the probability of varying demand in other months can be obtained.

After that, the occurrence probability of demand for each month is regarded as the weight to form a 33 - month demand sequence by randomly weighted sampling, and then this process is repeated 500 times to obtain 500 sequences. Next, formula (3) is used to calculate the accuracy $r$ of each requirement sequence, and then the sequence with the largest $r$ value is selected as the final demand sequence. This process of selecting the optimal demand sequence is repeated 10 times to obtain 10 sets of demand sequences, shown in Table 4.

Combining the data sequence in Table 4 and historical data as the source data, the lead-time requirement is fit. Under the situation where the significance level is 0.1 and the lead-time is one month, the lead-time demand distribution obeys the normal distribution.

As stated above, the lead-time demand distribution of the other four kinds of electric power supplies can also be obtained. The general situation is shown in Table 5 .

After determining the lead-time demand distribution of the power supplies, the safety inventory and reorder point can be analyzed to determine the inventory replenishment policy.

Taking material 1 as an example, according to the continuous inspection strategy, the average value of monthly demand is $\bar{R}=32$, the standard deviation is $\sigma_{R}=25$, the lead-time is $L=1$, and the cycle service level that should be satisfied is $90 \%$.

Since the demand for the lead-time of these goods is within a normal distribution, the average demand for the lead-time is:

$$
R_{L}=L \times \bar{R}=1 \times 32=32
$$

The lead-time demand standard deviation is:

$$
\sigma_{L}=\sqrt{L} \times \sigma_{R}=\sqrt{1} \times 25=25
$$

The safe inventory level is:

$$
s s=F_{s}^{-1}(C S L) \times \sigma_{L}=F_{s}^{-1}(0.9) \times 25=32
$$

The reorder point is:

$P O R=s s+R_{L}=32+32=64$

Reconstructed Demand Data

\begin{tabular}{|c|c|c|c|c|c|c|c|c|c|c|}
\hline & S1 & S2 & S3 & S4 & S5 & S6 & S7 & S8 & S9 & S10 \\
\hline Month 4 & 0 & 0 & 0 & 0 & 0 & 0 & 22 & 0 & 0 & 31 \\
\hline Month 5 & 0 & 0 & 0 & 0 & 0 & 0 & 0 & 0 & 34 & 16 \\
\hline Month 6 & 31 & 0 & 0 & 22 & 0 & 0 & 0 & 0 & 22 & 0 \\
\hline Month 7 & 0 & 0 & 0 & 0 & 0 & 31 & 0 & 41 & 0 & \\
\hline Month 8 & 0 & 7 & 7 & 0 & 0 & 34 & 0 & 45 & 3 & 7 \\
\hline Month 9 & 22 & 0 & 54 & 34 & 7 & 0 & 0 & 0 & 16 & 31 \\
\hline Month 10 & 45 & 0 & 50 & 0 & 41 & 42 & 27 & 0 & 42 & 27 \\
\hline Month 11 & 55 & 34 & 27 & 32 & 31 & 31 & 41 & 31 & 42 & 54 \\
\hline Month 12 & 54 & 55 & 41 & 72 & 32 & 41 & 41 & 55 & 15 & 3 \\
\hline Month 13 & 72 & 15 & 72 & 16 & 34 & 50 & 42 & 55 & 75 & 45 \\
\hline Month 14 & 16 & 16 & 34 & 16 & 87 & 42 & 7 & 42 & 15 & \\
\hline Month 15 & 46 & 42 & 54 & 21 & 50 & 21 & 0 & 54 & 50 & 0 \\
\hline Month 16 & 0 & 0 & 41 & 42 & 15 & 0 & 0 & 0 & 32 & \\
\hline Month 17 & 27 & 27 & 41 & 45 & 27 & 31 & 72 & 34 & 0 & 7 \\
\hline Month 18 & 55 & 32 & 41 & 34 & 16 & 42 & 3 & 3 & 32 & 14 \\
\hline Month 19 & 46 & 27 & 41 & 14 & 3 & 31 & 27 & 87 & 14 & 32 \\
\hline Month 20 & 75 & 41 & 90 & 46 & 50 & 16 & 46 & 27 & 41 & \\
\hline Month 21 & 46 & 27 & 3 & 41 & 75 & 0 & 41 & 31 & 32 & 46 \\
\hline
\end{tabular}


Jiahui Xu, Pingyu Liu, Xuemin Xu, Zhenni Huang, Wenshuang Zhao, Kwok Leung Tam, Aiping Jiang. The Research ...

\begin{tabular}{|c|c|c|c|c|c|c|c|c|c|c|}
\hline & S1 & S2 & S3 & S4 & S5 & S6 & S7 & S8 & S9 & S10 \\
\hline Month 22 & 27 & 16 & 75 & 15 & 16 & 55 & 55 & 55 & 7 & 42 \\
\hline Month 23 & 32 & 32 & 50 & 27 & 55 & 41 & 32 & 27 & 90 & 75 \\
\hline Month 24 & 27 & 21 & 14 & 32 & 54 & 46 & 45 & 15 & 72 & 0 \\
\hline Month 25 & 31 & 27 & 31 & 32 & 72 & 32 & 32 & 50 & 22 & 0 \\
\hline Month 26 & 50 & 45 & 54 & 75 & 22 & 3 & 16 & 3 & 14 & 15 \\
\hline Month 27 & 19 & 72 & 19 & 31 & 7 & 31 & 22 & 19 & 14 & 19 \\
\hline Month 28 & 75 & 27 & 54 & 45 & 19 & 32 & 34 & 21 & 32 & 0 \\
\hline Month 29 & 7 & 0 & 50 & 50 & 45 & 42 & 3 & 27 & 0 & 34 \\
\hline Month 30 & 21 & 42 & 21 & 54 & 21 & 7 & 34 & 21 & 32 & 42 \\
\hline Month 31 & 0 & 31 & 19 & 19 & 54 & 42 & 42 & 0 & 42 & 54 \\
\hline Month 32 & 31 & 34 & 55 & 34 & 0 & 0 & 0 & 34 & 0 & 0 \\
\hline Month 33 & 72 & 54 & 0 & 90 & 31 & 41 & 19 & 32 & 16 & 27 \\
\hline Month 34 & 31 & 21 & 32 & 15 & 32 & 54 & 16 & 75 & 31 & 7 \\
\hline Month 35 & 90 & 50 & 27 & 22 & 87 & 42 & 72 & 46 & 72 & 72 \\
\hline Month 36 & 75 & 31 & 90 & 19 & 72 & 34 & 72 & 46 & 87 & 15 \\
\hline
\end{tabular}

Table 5

Reconstructed Demand Data

\begin{tabular}{|c|c|c|}
\hline Material & Models & $\begin{array}{c}\text { Lead-time demand } \\
\text { distribution }\end{array}$ \\
\hline 500031139 & $\begin{array}{c}10 \mathrm{kV} \text { cable terminations, } 3 * 400, \\
\text { indoor terminals, prefabricated, } \\
\text { Cuprum }\end{array}$ & $\begin{array}{c}\text { Normal } \\
\text { distribution }\end{array}$ \\
\hline 500021270 & $\begin{array}{c}10 \mathrm{kV} \text { cable terminations, } 3 * 120, \\
\text { indoor terminals, prefabricated, } \\
\text { Cuprum }\end{array}$ & $\begin{array}{c}\text { Normal } \\
\text { distribution }\end{array}$ \\
\hline 500032513 & $\begin{array}{c}10 \mathrm{kV} \text { cable terminations, 3*240, } \\
\text { indoor terminals, prefabricated, } \\
\text { Cuprum }\end{array}$ & $\begin{array}{c}\text { Gamma } \\
\text { distribution }\end{array}$ \\
\hline 500021283 & $\begin{array}{c}10 \mathrm{kV} \text { cable terminations, 3*120, } \\
\text { outdoor terminals, prefabricated, } \\
\text { Cuprum }\end{array}$ & $\begin{array}{c}\text { Normal } \\
\text { distribution }\end{array}$ \\
\hline 500032519 & $\begin{array}{c}10 \mathrm{kV} \text { cable terminations, 3*70, } \\
\text { indoor terminals, prefabricated, } \\
\text { Cuprum }\end{array}$ & $\begin{array}{c}\text { Normal } \\
\text { distribution }\end{array}$ \\
\hline
\end{tabular}

The warehouse shall always ensure that the inventory of material 1 is at least 32 to ensure that the material inventory can meet the usage requirements in $90 \%$ of cases. When the inventory of material 1 is as low as 64 , the staff in charge shall make an order to the supplier.

\section{Conclusions}

\section{Summary}

To address the problem that lead-time distribution is difficult to obtain because of limited historical data, this paper proposes a method that reconstructs historical demand data by using a multivariate high-order Markov chain to expand the sample size of the data, and then obtain the lead-time demand distribution. The first step in the reconstruction process is to set the multiple states and their corresponding quantity of demand according to the frequency of occurrence of historical demand and standardized demand data intervals. Secondly, the selfcorrelation of the demand time series and the influence between each material are considered to construct multiple variable high-order Markov chain, which could obtain more accurate state probabilities to infer the result. In addition, when the state probabilities are determined, the demand quantity is not determined by the state of maximum probability; instead the random sampling with the probability of each state at each moment as the weight of the state is used to restructure the demand data which combine the lead-time information to fit the lead-time demand distribution. Through empirical research, this paper successfully fits the lead-time demand distribution to the power materials with only a small amount of historical data, and obtains the safety inventory and reorder point according to the distribution. This shows that the method proposed in this paper can effectively fit the lead-time demand distribution of less-historical-data materials and help enterprises to make reasonable inventory management decisions.

\section{Limitations}

The method proposed in this paper has two main limitations. Firstly, the final lead-time demand sequences for each repetition are not the same because this method adopts the weight-based random sampling after the demand sequence is finally determined, and sometimes the resulting sequences cannot fit the distribution. Therefore, the method should be repeated many times in order to ensure that the distribution of multiple fitting is stable and uniform. Secondly, in the process of data validation, some materials with a high frequency of zero demand cannot fit the data, even when a large amount of the data are reconstructed, so this method is only suitable for materials with a low proportion of zero demand, not for materials with limited historical data and a large quantity of zero demand.

\section{Outlook}

First of all, the lead-time demand distribution mentioned in this paper is based on a fixed lead-time. However, in practical application, the lead-time demand of many materials is not fixed, so the distribution cannot be obtained by busing the lead-time demand data which is simply summed after gaining the demand quantity. Therefore, in our follow-up study, expand the scope of this method should be expanded. We could combine the multivariate high-order Markov chain proposed in this paper with an enlarged sample size of demand data to fit the distribution with an unfixed lead-time. In addition, because this method emphasizes matching the quantity demanded to the state directly and restructuring historical period requirement intervals is achieved by weighted random sampling according to the state probability of occurrence, the effectiveness of this method in practical application largely depends on setting appropriate status of each material demand. The setting of state directly influences the reliability of the final fitted distribution. This paper sets up specific standards to divide the states of 
each material, which can be improved in future studies. A scientific criterion could be set to classify materials and divide their states, so that this method can be used for a large quantity of materials, which is significant in enhancing its value in real business practice.

\section{Disclosure Statement}

The authors declare that there are no conflicts of interest regarding the publication of this paper.

\section{Acknowledgments}

The research described in this paper has been funded by the National Natural Science Foundation of China (Grant No. $71871133)$.

\section{References}

Andersen, A. R., Nielsen, B. F., \& Reinhardt, L. B. (2017). Optimization of hospital ward resources with patient relocation using Markov chain modeling. European Journal of Operational Research, 260(3), 1152-1163. https://doi.org/10. 1016/j.ejor.2017.01.026

Archibald, B., \& Silver, E. (1978). (s,S) Policies under Continuous Review and Discrete Compound Poisson Demand. Management Science, 24(9), 899-909. https://doi.org/10.1287/mnsc.24.9.899

Babai, M. Z., Jemai, Z., \& Dallery, Y. (2011). Analysis of order-up-to-level inventory systems with compound poisson demand. European Journal of Operational Research, 210(3), 552-558. https://doi.org/10.1016/j.ejor.2010.10.004

Chandra, C., \& Grabis, J. (2005). Application of multi-steps forecasting for restraining the bullwhip effect and improving inventory performance under autoregressive demand. European Journal of Operational Research, 166(2), 337-350. https://doi.org/10.1016/j.ejor.2004.02.012

Chelbi, A., \& Ait-Kadi, D. (1999). An optimal inspection strategy for randomly failing equipment. Reliability Engineering and System Safety, 63(2), 127-131. https://doi.org/10.1016/S0951-8320(98)00031-3

Chen, Y., Liu, Y. \& Jiang, T., (2021). Optimal maintenance strategy for multi-state systems with single maintenance capacity and arbitrarily distributed maintenance time. Reliability Engineering \& System Safety, 211, 107576. https://doi.org/10.1016/j.ress.2021.107576

Cheung, K. L. (1996). On the (S-1, S) inventory model under compound poisson demands and i.i.d. unit resupply times. Naval Research Logistics, 43(4), 563-572. https://doi.org/10.1002/(SICI)1520-6750(199606)43:4<563::AIDNAV8>3.0.CO; $2-5$

Chiachio, J., Jalón, M., Chiachío, M. \& Kolios, A., (2020). A Markov chains prognostics framework for complex degradation processes. Reliability Engineering \& System Safety, 195, 106621. https://doi.org/10.1016/j.ress.2019 .106621

Ching, W., Fung, E. \& Ng, M., (2004). Higher-order Markov chain models for categorical data sequences. Naval Research Logistics, 51(4), 557-574. https://doi.org/10.1002/nav.20017

Ching, W., (2002). A multivariate Markov chain model for categorical data sequences and its applications in demand predictions. IMA Journal of Management Mathematics, 13(3), 187-199. https://doi.org/10.1093/imaman/13.3.187

Ehrhardt, R. (1979). The Power Approximation for Computing (s, S) Inventory Policies. Management Science, 25(8), 777-786.

Elsayed, E. A., \& Teresi, C. (1983). Analysis of inventory systems with deteriorating items. International Journal of Production Research, 21(4), 449-460. https://doi.org/10.1080/00207548308942381

Feeney, G., \& Sherbrooke, C. (1966). The (S - 1, S) Inventory Policy under Compound Poisson Demand. Management Science, 12(5), 391-411. https://doi.org/10.1287/mnsc.12.5.391

Feldman, J. B., \& Topaloglu, H. (2017). Revenue Management under the Markov Chain Choice Model. Operations Research, 65(5), 1322-1342. https://doi.org/10.1287/opre.2017.1628

He, Z., \& Jiang, W. (2017). A new belief Markov chain model and its application in inventory prediction. International Journal of Production Research, 56(8), 2800-2817. https://doi.org/10.1080/00207543.2017.1405166

Karapetyan, D., Punnen, A. P., \& Parkes, A. J. (2017). Markov chain methods for the bipartite boolean quadratic programming problem. European Journal of Operational Research, 260(2), 494-506. https://doi.org/10.1016/ j.ejor.2017.01.001 
Jiahui Xu, Pingyu Liu, Xuemin Xu, Zhenni Huang, Wenshuang Zhao, Kwok Leung Tam, Aiping Jiang. The Research ...

Kocer, U. U. (2013). Forecasting intermittent demand by Markov chain model, International Journal of Innovative Computing. Information and Control, 9(8), 3307-3318.

Kourentzes, N. (2013). Intermittent demand forecasts with neural networks. International Journal of Production Economics, 143(1), 198-206. https://doi.org/10.1016/j.ijpe.2013.01.009

Larsen, C., \& Thorstenson, A. (2008). A Comparison between the Order and the Volume Fill Rate for a Base-Stock Inventory Control System under a Compound Renewal Demand Process. Journal of the Operational Research Society, 59(6), 798-804. https://doi.org/10.1057/palgrave.jors.2602407

Leven, E., \& Segerstedt, A. (2004). Inventory control with a modified Croston procedure and Erlang distribution. International Journal of Production Economics, 90(3), 361-367. https://doi.org/10.1016/S0925-5273(03)00053-7

Liu, L., \& Lian, Z. (1999). (s, S) continuous review models for products with fixed lifetimes. Operations Research, 47(1), 150-158. https://doi.org/10.1287/opre.47.1.150

Naddor, E. (1975). Optimal and Heuristic Decisions in Single- and Multi-Item Inventory Systems. Management Science, 21(11), 1234-1249. https://doi.org/10.1287/mnsc.21.11.1234

Pilinkiene, V. (2008). Selection of market demand forecast methods: Criteria and application. Inzinerine EkonomikaEngineering Economics, 58(3), 19-25.

Porteus, E. L. (1985). Numerical comparisons of inventory policies for periodic review systems. Operations Research, 33(1), 134-152. https://doi.org/10.1287/opre.33.1.134

Roberts, D. M. (1962). Approximations to Optimal Policies in a Dynamic Inventory Model, In Studies in Applied Probability and Management Science, K. Arrow, S. Karlin and H. Scarf (eds). Stanford University Press, Stanford, 207-229.

Sani, B., \& Kingsman, B. G. (1997). Selecting the best periodic inventory control and demand forecasting methods for low demand items. Journal of the Operational Research Society, 48(7), 700-713. https://doi.org/10.1038/ sj.jors.2600418

Silver, E. A. (1965). Bayesian Determination of the Reorder Point of a Slow Moving Item. Operations Research, 13(6), 989-997. https://doi.org/10.1287/opre.13.6.989

Smith, M. A. J., \& Dekker, R. (1997). On the (S-1,S) stock model for renewal demand processes: Poisson's poison. Probability in the Engineering and Informational Sciences, 11(3), 375-386. https://doi.org/10.1017/S02699 64800004897

Snyder, R. (2002). Forecasting sales of slow and fast moving inventories. European Journal of Operational Research, 140(3), 684-699. https://doi.org/10.1016/S0377-2217(01)00231-4

Strijbosch, L., Heuts, R., \& Van der Schoot, E. (2000). A Combined Forecast-Inventory Control Procedure for Spare Parts. Journal of the Operational Research Society, 51(10), 1184-1192. https://doi.org/10.1057/ palgrave.jors.2601013

Su, C. T., \& Wong, J. T. (2008). Design of a replenishment system for a stochastic dynamic production forecast lot-sizing problem under bullwhip effect. Expert Systems with Applications, 34(1), 173-180. https://doi.org/10.1016/ j.eswa.2006.08.010

Teunter, R., \& Sani, B. (2009). Calculating order-up-to levels for products with intermittent demand. International Journal of Production Economics, 118(1), 82-86. https://doi.org/10.1016/j.ijpe.2008.08.012

Teunter, R. H., Syntetos, A. A., \& Babai, M. Z. (2010). Determining order-up-to levels under periodic review for compound binomial (intermittent) demand. European Journal of Operational Research, 203(3), 619-624. https://doi.org/10. 1016/j.ejor.2009.09.013

Veinott, A. F., \& Wagner, H. M. (1965). Computing Optimal (s, S) Inventory Policies. Management Science, 11(5), 525552. https://doi.org/10.1287/mnsc.11.5.525

\section{Author Biographies}

Jiahui Xu is a native of Taizhou, Zhejiang. Now he is an undergraduate in SHU - UTS SILC Business School, Shanghai. Shanghai. His main research interests are demand forecasting and inventory management. ORCID: 0000-00016772-3957.

Pingyu Liu is a native of Shanghai. Now she is an undergraduate in SHU - UTS SILC Business School, Shanghai University. Her main research interests relate to demand forecasting and inventory management. 
Xuemin Xu is a native of Xingtai, Hebei. She graduated from Shanghai University. Now she is a lecturer in the SHUUTS SILC Business School, Shanghai University, PRC. She was a visiting scholar at Carlton University in the United States, Sydney University of Technology in Australia and Angles College in Australia. Her main research interests are related to demand forecasting and inventory management.

Zhenni Huang is a native of Shanghai. She is a postgraduate in SHU - UTS SILC Business School (Master's Degree in Management Science and Engineering), Shanghai University. Her main research interests are demand forecasting and inventory management.

Wenshuang Zhao is a native of Shandong. He is a postgraduate in SHU - UTS SILC Business School (Bachelor' s Degree in International Economy and Trade), Shanghai University. His main research interests is optimization.

Kwok Leung Tam is a native of Hongkong; Dr. He graduated from the Department of Statistics, Columbia University. $\mathrm{He}$ is a teacher in the School of Mathematics and Statistics, UNSW, Sydney NSW, Australia. His main research interests are related to demand forecasting.

Aiping Jiang (corresponding author) is a native of Longkou, Shandong, a professor. She graduated from the Department of Applied Mathematics, Tongji University. She is an associate professor in the SHU - UTS SILC Business School, Shanghai University. She is also a distinguished research fellow at the Demand Chain Management Laboratory of Modern Logistics Research Center, Shanghai University. Her research interests include demand forecasting and inventory management etc.. She takes charge of the national natural science fund project (71871133). ORCID: 0000-0002-4822-9627.

The article has been reviewed. Received in September 2020; accepted in October 2021.

This article is an Open Access article distributed under the terms and conditions of the Creative Commons Attribution 4.0 (CC BY 4.0) License (http://creativecommons.org/licenses/by/4.0/). 